\title{
Research on the Countermeasures to Accelerate the Construction of Independent Innovation Ability of Shandong Province
}

\author{
Peizhe Li ${ }^{1,2, \text { a }^{*} \text {, Shanshan Pei }}{ }^{1, b}$ \\ ${ }^{1}$ School of Business, Shan Dong University of Political science and Law, Jinan 250014, China; \\ ${ }^{2}$ College of Economics and Management, Nanjing University of Aeronautics and Astronautics, \\ Nanjing 210016, China; \\ *Corresponding author Email: lipeizhe713@163.com, beishan616@163.com
}

Keywords: independent innovation, evaluation, Industry-University-Institute Cooperation.

\begin{abstract}
Improving the ability of independent innovation is an important way to realize the transformation of economic development mode and improve the comprehensive competitiveness of the region. Evaluating of the independent innovation ability of four provinces in eastern China by using factor analysis method, the results showed that the comprehensive score of independent innovation ability of Shandong still have a certain gap compared with Guangdong, Jiangsu and other regions; Finally, based on the analysis of the existing problems in Shandong Province, the countermeasures and suggestions were put forward to accelerate the construction of independent innovation ability in Shandong province.
\end{abstract}

\section{Introduction}

Innovation is the first driving force to lead the development and the strategic support for the construction of a modern economic system. Strengthening the ability of independent innovation is the core of changing the way of economic growth, and is the key to improve the regional comprehensive competitiveness. In recent years, Shandong's economy has achieved rapid development. But many industries are still not strong in innovation. Low innovation accounts for a large proportion. The self-sufficiency rate of key technology is relatively low, and in the division of labor is still at the initial stage, lacking the power of continuous development. So, because of the request from the nature of the new industrialization strategy and sustainable development of Shandong, to realize the harmonious and sustainable development of economy and society, we must rely on independent innovation, improve the high-end technology and core technology research and development capabilities, to better enhance the comprehensive competitiveness of Shandong Province, to obtain the competitive advantage in the market economy. Therefore, systematic research on Shandong's independent innovation capability is of great practical significance for further exploring the potential advantages and resources of Shandong's technological innovation, enhancing Shandong's innovation ability and regional competitive advantage.

At present, the international research on regional innovation ability is mainly focused on the innovation policy and the establishment of the innovation system. Rothwell (1992) put forward the integrated innovation policy, integration is "scientific innovation policy" and "industrial innovation policy" as a whole based on the analysis of the European science and technology policy change process; Naushad Forties, David Wield (2000) pointed out that independent innovation is an important task of general technology catch-up, technology catch-up and leading technology the research methods are different; Guan (2003) pointed out that technological innovation capability includes products, technology, knowledge, and innovation ability is divided into multiple dimensions, that technological innovation is a kind of special resources; Burgelman (2004) argues that technological innovation capability can effectively support and promote the implementation of the strategy of enterprise technology innovation. The research of domestic scholars mainly concentrates on the way of improving the ability of independent innovation and the evaluation of the ability of 
innovation. Ge Jintian (2014) put forward to accelerate the pace of technological innovation and enhance the ability of independent innovation strategy based on the analysis of the development trend of world science and technology innovation and advanced area on the successful experience; Yang Qingfeng (2013) analysis the evaluation of innovation efficiency of regional high technology industry with the model evaluation by 1995-2009 years of China's Regional Panel data; Yang Yi, Xue Huijuan (2011) constructed the technological innovation capability evaluation index system from the aspects of input ability, output ability and support ability.

The comprehensive survey of domestic and foreign researches on regional independent innovation capacity has made many useful attempts, both theoretically and practically, and has greatly promoted the research of independent innovation. However, the research on independent innovation is still at a preliminary stage, and the research on provincial regional independent innovation capability is not deep enough. The breakthrough point of practical application has not been found. Therefore, the current research on independent innovation can not meet the needs of promoting regional independent innovation ability and promoting the sustainable development of economic and social health. The object of this study is mainly based on the regional level of independent innovation, independent innovation of regional independent innovation and single subject. there is great difference between the single main body of independent innovation, focus on their own innovative activities, and regional independent innovation means not only rely on their own resources and capacity for independent innovation, can also use the resources within the region together with regional innovation, including other enterprises, universities, research institutes and other innovation integrated innovation, to integrate internal and external resources, to carry out research and development activities, key technologies and common technologies and forward-looking technology breakthrough, realize the upgrading of the industrial structure adjustment and economic transformation, and improve the comprehensive competitiveness of the region. This paper analyses the current situation of independent innovation in Shandong Province, mining in Shandong province in the independent innovation problems and restricting factors, and puts forward some countermeasures and suggestions to speed up the independent innovation ability of Shandong province construction, in order for the relevant decision-making departments and innovation to provide a reference in independent innovation, has a strong practical significance.

\section{The Status of Independent Innovation in Shandong Province}

Shandong Province has developed a number of documents depicts a long time phased goal according to the actual situation and the overall economic development, formed a development vision: Shandong will build a strong economic and cultural innovation driven, highly developed information and sustainable development, a comprehensive well-off society in 2020. In recent years, the pace of technological innovation has accelerated significantly with the further implementation of various preferential policies in Shandong, which has made an important contribution to the rapid and sustained development of the economy.

(1) Factor input and main scientific and technological output. In 2013, the total R\&D investment was 117 billion 580 million 270 thousand yuan in the province, and R\&D personnel were fully equivalent to 279331 people and 76796 patents were authorized. In 2014, the high and new technology industry above the scale increased by $13.5 \%$, and the proportion of the industrial output value above the scale reached $31.33 \%$.

(2)The capacity building of independent innovation. The achievements of scientific and technological innovation were obvious in 2014 in Shandong province. 2955 items of scientific and technological achievements were registered. Won 3 National Natural Science Awards, 5 national technology invention awards, 20 national science and technology progress awards, 159 thousand patent applications, including 14.3\% invention patents applications, 73 thousand authorized patents, and the invention patent license increased $18.2 \%$ over last year. There were 154 items of independent innovation and transformation of achievements, and 17474 technical registration contracts, with a turnover of 26 billion 900 million yuan, and increased of $42.6 \%$. 
(3) Policy guarantee. The continuous improvement of scientific research project management and reform plan of science and technology, the establishment of venture capital funds, issued the "Shandong province science and technology achievement transformation pilot fund management Interim Measures"; to further play the role of science and technology venture investment fund, established on "Improve and strengthen the construction of provincial key Laboratory of opinions" and the implementation of innovation platform management mode.

In recent years, although the pace of innovation of science and technology province increased significantly in Shandong, but the technological innovation is still at a low level, mainly rely on the consumption of resources, cheap labor, high investment and high consumption of the extensive mode of economic growth; there are still insufficient investment in science and technology, science and technology output structure unreasonable, the development efficiency is not high, the contribution rate of science and technology is low. Obviously, the traditional way of economic development is difficult to achieve the vision of Shandong's development. We must improve the capability of independent innovation to achieve the transformation of Shandong's economic development mode and enhance its comprehensive competitiveness.

\section{Evaluation of Independent Innovation Ability of Shandong Province}

The high-tech industry is one of the most active and innovative industries in the regional economy. The innovation ability of the high-tech industry largely affects the innovation ability of a region. Therefore, the ability of independent innovation in high tech industry as an example to evaluate the four provinces including Shandong, Jiangsu, Zhejiang and Guangdong, the selected data from "Statistical Yearbook on science and technology" and "Chinese Chinese High-tech Industry Statistical Yearbook"in 2015, selected according to scientific and feasible principles of indicators, selection of 14 indicators including high technology enterprise the number of main business income, profits, R\&D number, R\&D number, $R \& D$ personnel or personnel FTE and R\&D expenditures and R\&D items, R\&D projects and new product development projects, the number of new product sales revenue, expenditure of new products, the number of patent applications, valid invention patents. The factor analysis method was used for comprehensive evaluation. The KMO and Bartlett tests were suitable for factor analysis.

The comprehensive evaluation model of regional high-tech industry innovation capability:

$$
f=\frac{\left(w_{1} f_{1}+w_{2} f_{2}+w_{3} f_{3}\right)}{\left(w_{1}+w_{2}+w_{3}\right)}
$$

$f$ is the comprehensive score,$w_{i}$ is the variance contribution rate of the $i$ public factor.

Using spss20.0 software to make factor analysis, three common factors were extracted. Among them, the common factor 1 was named activity base and input-output factor. The common factor 2 was named as the output capacity factor, and the common factor 3 was named the output efficiency factor. The final evaluation results are shown as shown in Table 1.

Table 1 The score and ranking of four provinces

\begin{tabular}{ccccccccc}
\hline Region & $\begin{array}{c}\text { Common } \\
\text { factor1 }\end{array}$ & Ranking & $\begin{array}{c}\text { Common } \\
\text { factor2 }\end{array}$ & Ranking & $\begin{array}{c}\text { Common } \\
\text { factor3 }\end{array}$ & Ranking & $\begin{array}{c}\text { Comprehensive } \\
\text { score }\end{array}$ & Ranking \\
\hline Jiangsu & 2.53 & 2 & -0.71 & 4 & -0.08 & 4 & 1.65 & 2 \\
Zhejiang & 0.63 & 4 & 1.04 & 1 & 0.61 & 1 & 0.59 & 3 \\
Shandong & 0.65 & 3 & 0.63 & 2 & -0.01 & 3 & 0.51 & 4 \\
Guangdong & 4.32 & 1 & 0.49 & 3 & 0.12 & 2 & 3.03 & 1 \\
\hline
\end{tabular}

On the basis of factor interpretation, combined with table 1 and related source data, we can get the ranking of the high-tech industry innovation ability in all the Common factors in four provinces.

(1) In the base of activities and input-output factors, Shandong was ranked third, and the top 2 were Guangdong and Jiangsu. It shows that the high technology industry has a good foundation in Shandong, but there is still a gap between the investment and output in Guangdong and other areas. 
(2) In the output capacity factor, Shandong ranked the second place, indicating that Shandong has strong output capacity. Next, we should make rational use of innovative resources, further improve R\&D fund utilization and improve output capacity, especially increase output capacity of new products.

(3) The output efficiency factor, Shandong province ranked third place, showed that R\&D funds utilization ratio and output rate is not high, should change the mode of development, scientific and rational allocation of resources, improve the level of output and efficiency, so as to play its role in the harmonious development of regional economy.

In the four provinces, the overall score of independent innovation ability of high-tech industry in Shandong province ranked fourth place, indicating that Shandong's independent innovation ability is still have a certain gap compared with Guangdong, Jiangsu and other regions. From the level of overall innovation ability, the high technology industry foundation of Shandong is better, but the output capacity and output efficiency of new products and units are low. The next step should be to seize the weak links, classify management, strengthen efforts, and further narrow the gap with Guangdong, Jiangsu and other regions.

\section{Measures to Accelerate the Construction of Independent Innovation ability}

(1) Improve the understanding of the importance of scientific and technological innovation

Many developed areas have made beneficial explorations in improving independent innovation platform, technological innovation system, and training scientific and technological innovation talents, and achieved good results, effectively promoting the sustainable and healthy development of the economy, which has important reference significance. Shandong province in the use of funds supervision, the efficiency of science and technology innovation, innovation subject innovation enthusiasm, risk control is still not perfect, this needs to be combined with the actual Shandong, to further enhance the understanding of the importance of technological innovation, the technological innovation as an important means to enhance the comprehensive competitiveness.

(2) Strengthening the construction of independent innovation culture

The innovation of science and technology workers should be fused into the daily life and work, form a kind of innovation, tolerance of failure, good innovation and cultural environment; at the same time, to respect the laws of innovation, establish a scientific and reasonable evaluation mechanism innovation; technological innovation need to have perfect system guarantee, should actively promote the construction of system and management innovation ability to improve the overall enthusiasm for technological innovation, improve the output efficiency of scientific and technological achievements, to ensure the smooth process of technological innovation.

(3) Increase investment in scientific and technological innovation

The data show that the proportion of R\&D in Shandong in 2013 is about $2.1 \%$ of GDP, and the gap is still large compared with the advanced provinces. Therefore, to continuously improve the scientific and technological innovation, and establish a stable growth mechanism, increase the technology innovation support, such as the establishment of special funds for supporting the assessment by the, potential and development prospect of the technology, research focusing on key technology, common technology and forward-looking technology.

(4) Strengthening the construction of science and technology intermediary

At present, the functions and functions of innovation and cooperation of various intermediary agencies in Shandong province are not ideal, mainly due to the unclear status of science and technology intermediary service institutions, non-standard organizations and imperfect supervision. The government should formulate corresponding policies, and promote the healthy development of science and technology intermediary industry; at the same time, increase support for training of high-quality science and technology intermediary service personnel, and continuously improve service quality and level of science and technology intermediary organization, maximize the role of science and technology intermediary.

(5) Perfect the system of cooperation and innovation of production, school and research 
Enterprises should speed up the establishment of an enterprise R\&D mechanism, guide innovation resources to enterprises, and form an innovative system with market orientation, business as the main body and industry, University and research integration, so as to form an integrated innovation advantage; at the same time, to further improve the cooperation of the distribution of benefits and risk sharing mechanism, improve the enthusiasm of innovation, give full play to the main innovation of enterprises, universities, research institutions and other advantages, improve the integration level of innovation.

\section{Acknowledgements}

This work was financially supported by the Social science planning research project of Shandong(14BGLJ07); the Research of the Theory and Practice of Ideological and Political Education of Shan Dong University of Political science and Law: Research on the application of flexible management of the education of college Students; Research on network moral education of college students; the Scientific research project of Shan Dong University of Political science and $\operatorname{Law}(2015 Z 03 B)$.

\section{References}

[1] Rothwell, Successful Industrial Innovation:Critical Factors for the 1900s [J].R\&D Management, 1992.22 ( 3): 221-239.

[2] Naushad Forties, David Wield, Managing R\&D in Technology-followers [J].Research Policy, 2000(29):47-53.

[3]GuamJ.,Innovative Capability and Export Performance of Chinese Firms[J]. echnovation ,2003(9): 737-747.

[4] Burgelman, R., Strategic Management of Technology and Innovation[M]. McGraw-Hill, New York, 2004.

[5] Ge Jintian. The research to promote economic transformation and upgrading of Scientific and technological innovation [J].Dongyue Tribune 2014 (12): 144-147.

[6] Yang Qingfeng. Determinants of R\&D efficiency in high tech industry areas - Empirical Analysis based on random frontier model[J]. Management review, 2013 (6): 47-58.

[7] Yang Yi, Xue Huijuan. Study on regional difference of independent innovation ability of industrial technology [J]. Chinese industrial economy, 2011 (11): 68-76.

[8] Feng Weiyi, Li Jianhua, Zhao Shukuan. The influence of technological innovation on the competitiveness of high-tech industry -- Based on the empirical analysis of 1995-2010 years data in China, [J]. Chinese Soft Science, 2012 (9): 154-164.

[9] Fang Yi, Lin Xiu Mei. Research on dynamic efficiency of research and development of high technology industry in China [J]. Application of Statistics and Management, 2012 (15): 761-770.

[10]J.A.Schumpeter. The theory of economicdevelopment[M],Cambridge: Harvard University Press,1912.

[11]Drunker. The Practice of Management[M], Cambridge:Harvard University Press,1955. 